\title{
For success, focus your strengths
}

\section{Balancing opportunism with focused goals is perhaps the hardest lesson of all.}

\section{Arthur D. Levinson}

Though Genentech (South San Francisco, CA) is a 22-year-old biotechnology pioneer, with more than 3,200 employees, 7 marketed products, a large pipeline of potential products, and more than a billion dollars in revenues, I believe we have relevant advice to offer the young, small, entrepreneurial biotechnology companies of today. After all, Genentech was itself such a company, and our corporate culture today still strongly reverberates with the spirit of those exciting beginnings.

However, along the way to our current success, we have learned a fundamental concept that might seem counter to entrepreneurial enthusiasm, but is, in fact, a key to harnessing it: Focus. This is a simple concept, but is easy to lose sight of through every step of building a biotechnology business. Famed management consultant Peter Drucker once said, "When you have 186 objectives, nothing gets done." He was correct.

\section{The first bioentrepreneurs}

In 1976, venture capitalist Robert A. Swanson and biochemist Herbert W. Boyer pioneered the concept of being a bioentrepreneur when they decided to start a new kind of company. During a now-legendary three-hour conversation, Swanson and Boyer concluded that the recent breakthroughs in recombinant DNA technology that Boyer had helped discover had commercial potential. As a result of that meeting, Genentech was born.

Initially, it was easy for the fledgling company to focus its scientific efforts. Its scientists had one goal: Clone a human protein that was relatively easy, if not therapeutically relevant, so they could prove its scientific feasibility and obtain funding to grow the company. It worked. When they cloned somatostatin, a brain hormone, in 1977 they proved that human proteins could be produced in and harvested from microorganisms.

With this proof of concept achieved, they focused their efforts on pursuing the most obviously needed pharmaceutical proteinsthose that would replace proteins missing or

Arthur D. Levinson is president and CEO

of Genentech, Inc., 1 DNA Way, South

San Francisco, CA 94080.
Famed management consultant Peter Drucker once said, "When you have 186 objectives, nothing gets done." He was correct.

in short supply in certain medical disorders-such as insulin. Again, it worked. In 1982, insulin, which Genentech licensed to Eli Lilly (Indianapolis, IN), became the first marketed product of biotechnology. Three years later, Genentech became the first biotechnology company to market a product by itself when it introduced Protropin (somatrem for injection) growth hormone.

What drove these initial successes was outstanding science. As mavericks in their fields, Swanson and Boyer instinctively knew that their scientists would be most productive only if given the kind of intellectual freedom they could enjoy in an academic setting. At the time, this was revolutionary concept for a business.

It proved to be a visionary coup. Our unfettered scientists pursued opportunity after opportunity that soon filled our product development pipeline to capacity. With more potential products than we could handle with our available funding, we outlicensed some and spun off others. This approach to drug development steered us toward our initial market areas.

After our first endocrinology product, growth hormone, we entered the cardiovascular medicine arena with the approval of our thrombolytic heart attack treatment, Activase (recombinant alteplase) in 1987. We have continued to build upon our expertise and have developed a well-respected presence in these therapeutic areas as a result.

\section{Developing criteria for R\&D}

By the early 1990s, the bioentrepreneurial drive of Genentech's researchers posed a dilemma for the company's future. As we learned over the years, the financial realities of the marketplace would not allow us to pursue every research opportunity into development. Yet, we needed to preserve a core asset of our business: The innovation that comes in an environment where scientific freedom is held sacred.

Around the time I assumed leadership of research at Genentech, we launched an effort to examine in detail all of the projects that used a significant proportion of our scientific infrastructure. From this, we established a way to rate projects based on scientific feasibility, medical need, market potential, market protection, and manufacturing economy.

To ensure that the company would have the resources available to back the most promising projects, we decided to move forward only with those projects that met our criteria for all five of these considerations. In so doing, we terminated more than half of our research projects. We used these same criteria to determine which projects to move into and to continue through clinical development.

With our discovery research and clinical scientists accustomed to considering only some of these criteria, this was not an easy task. But over time, Genentech's scientists came to recognize the benefit of considering medical need and market and manufacturing realities relatively early in the process. It is far worse to have an exciting fortuitous discovery dropped at a later stage because there are simply not enough resources available, than to have an agreement upfront that as long as your project meets these criteria, Genentech will pursue it. In this way, we still encourage our scientists to use their unique backgrounds and skills to develop novel areas of research.

\section{Defining therapeutic areas}

Using these criteria, by 1995, around the time I assumed leadership of Genentech, we were working on entering an entirely new market for us, cystic fibrosis. We took great pride in the fact that our new medicine, Pulmozyme (dornase alfa) Inhalation Solution, was the first new therapy for cystic fibrosis patients in 30 years.

Because of the unique nature of cystic fibrosis treatment, which is concentrated in relatively few specialized treatment centers, when we launched Pulmozyme we were not able to capitalize fully on our existing market strengths and relationships. Furthermore, Genentech was now in a position where it had a variety of excellent products coming 
out of its discovery research efforts. This allowed us to be even more selective in our choice of development candidates. We also now had the financial resources to in-license other opportunities.

Given these facts, I felt, and my management team and the board of directors agreed, that Genentech should actively focus its efforts in specific therapeutic areas where we felt we had established strengths. The therapeutic areas of focus we identified are endocrinology, cardiovascular medicine, and oncology. Yet, once again, we needed to strike a balance. We knew that establishing such a focus would be essential to take Genentech to the next stage of significant growth, but we also wanted to remain opportunistic related to exciting new possibilities that might come out of our discovery research efforts-those for which it clearly would be worth breaking into new markets. Thus, our fourth area of focus is opportunistic projects.

While endocrinology and cardiovascular medicine may seem obvious therapeutic area choices, based on the company's history, oncology, especially to people outside of Genentech, may not have appeared to be one of our strengths, as we had no presence in the oncology market at the time.

\section{Timing is everything}

Although at Genentech I had been exploring the role of oncogenes in cancer development since 1980, until a few years ago, I would have been one of the first to tell you that Genentech should not be actively focusing on bringing cancer medicines to market. The technology simply wasn't ready, and the chance of success was then far too low.

But in recent years, there has been a great deal of progress in identifying cell-surface proteins involved in cancer and in producing humanized monoclonal antibodies targeting these proteins. By the early 1990s, early clinical results from a precursor of our own potential medicine-Herceptin (Trastuzumab) antiHER2 monoclonal antibody, which targets a cancer-related cell-surface protein called HER2-first convinced me that Genentech was at the forefront with a technology that offered an acceptable chance of success.

Following several years of clinical testing, the US Food and Drug Administration (FDA; Rockville, MD) recently designated Herceptin a fast track product for the treatment of metastatic breast cancer. This designation may help ensure a rapid review of regulatory filings seeking market clearance. We are working closely with the FDA to begin submitting portions of the biologics license application (BLA) for Herceptin, with completion of filing on target for the second quarter of this year.

In the meantime, working with our partner IDEC Pharmaceuticals (San Diego, CA), we brought to market another monoclonal antibody targeting a cancer-related cell-surface protein. In 1997 we launched Rituxan (Rituximab) for the treatment of relapsed or refractory low-grade or follicular, CD20 Bcell non-Hodgkins lymphoma. Rituxan was the first monoclonal antibody approved for therapeutic use in cancer in the United States.

On the basis of these two results, and other potential products in our pipeline, oncology has become an area of therapeutic focus for us. But we had to allow the technology to mature for nearly 15 years before we could capitalize on our strengths. Therefore, timing is everything in this area: Too much earlier, and we would have risked failure by taking a technology prematurely into the clinic; too much later, and we would have risked competitors taking over that segment of the market.

\section{From the beginning, Genentech has understood the need to focus. But understanding something and consistently acting upon it are two different things. It took experiencing the problems brought on by lack of focus to compel us to make focus a priority of our business planning.}

\section{Poised for the future}

Our efforts to focus our research and development based on criteria that gauge the potential for success and on therapeutic areas is working. We have a robust product pipeline that builds upon core competencies in our three areas of strategic focus. We also have preserved the ability to innovate into new areas with opportunistic projects.

For example, our cardiovascular portfolio reflects a strategy to shift from enhancing our acute thrombolytic position to move into a broader acute and chronic "circulation" portfolio. Our cardiovascular products offer the potential to use different approaches to treat or prevent cardiovascular ischemia and its complications.

In our endocrinology portfolio, an encapsulated sustained-release growth hormonewhich we are developing with partner Alkermes (Cambridge, MA)—builds upon our long-standing success in treating growth disorders. The endocrinology portfolio also expands our efforts into diabetes, with two potential medicines that target complications of this chronic disease.
In oncology, besides Herceptin, we have another humanized monoclonal antibody that recently began phase II trials for the potential treatment of several types of cancer, based on its ability to inhibit blood vessel formation thought to be needed for tumor development.

The other potential products rounding out our product portfolio represent opportunistic areas too good to pass up that fall outside our three defined therapeutic focus areas. For example, an anti-IgE antibody, which we are developing with partners Novartis (Basel, Switzerland) and Tanox Biosystems (Houston, TX), is a potential entry into the allergy/asthma market.

\section{Conclusions}

From the beginning, Genentech has understood the need to focus. But understanding something and consistently acting upon it are two different things. It took experiencing the problems brought on by lack of focus to compel us to make focus a priority of our business planning. In the early years of our business, we had a selective focus on some aspects of our activities, both scientific and otherwise. Now we have a more organized focus, throughout the company, with all areas recognizing their role in meeting our goals.

Initially, we were driven to develop this organized focus by fiscal realities, but now we do so because it has proven to make us into a stronger business. Over the years, in part through our own mistakes, we have learned that it is necessary to keep reexamining every aspect of our business-even beyond research and development - to make sure that it is as sharply focused on our talents and opportunities as possible.

I recommend this strategy to all bioentrepreneurs. Playing to your strengths will increase your chance of success, as it has for Genentech. Begin by focusing your efforts on projects with the greatest chance of scientific, medical, manufacturing, and commercial success. Take those projects in which you find research success and develop them into a platform for defining therapeutic areas in which your company can be an important player, while remaining open to opportunistic R\&D opportunities. This is particularly important for smaller companies today that have the added challenge of differentiating themselves from one another, a problem Genentech did not face. With several companies working on similar projects, the only thing that will set you apart is your science and your focused management. Finally, be patient with promising areas where you have strong leads; the technology may not yet be ready. When it is, and you are in a position to lead into the market with it, it will have been worth the wait. 